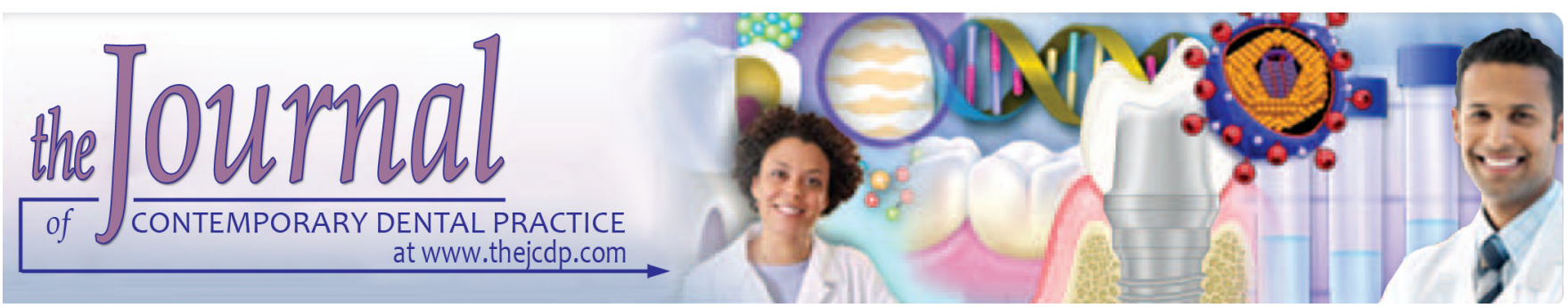

\title{
Influence of Image Filters and Variation in Horizontal Angle of Incidence of X-ray Beam in Digital Interproximal Radiographs for Diagnosis of Secondary Caries in Esthetic Restorations
}

\author{
${ }^{1}$ Lucas de Carvalho Deprá, ${ }^{2}$ Lilian Cristina Vessoni Iwaki, ${ }^{3}$ Mariliani Chicarelli, ${ }^{4}$ Wilton Mitsunari Takeshita
}

\begin{abstract}
Background: Secondary or recurrent caries are located around restoration margins or under these lesions, and can lead to tooth loss. The interproximal or bite wing radiograph is the technique of choice to assist diagnosis of secondary caries.

Objective: To evaluate diagnostic accuracy of secondary caries in pulpal walls artificially created in extracted human premolars, observed in digital bitewing radiographs using variations in horizontal X-ray beam angle of incidence and application of enhancement filters.
\end{abstract}

Materials and methods: The sample consisted of 20 healthy premolars, in which secondary caries lesions were simulated by means of subjecting the pulpal wall of the cavity to wear with spherical carbide drill half, fitted to a high speed handpiece, under constant cooling, focused perpendicular to the tooth surface. The orifices were filled with wax and all teeth were restored with composite resin Filtek $Z 350 \times \mathrm{XT}^{\circledR}$. Later teeth were radiographed with a digital sensor complementary metal-oxidesemiconductor (CMOS) varying the horizontal angle at intervals of $2^{\circ}$, covering a range of -10 to $+10^{\circ}$.

Results: The results showed that in the diagnosis of secondary caries, there was no statistically significant difference between the 2 pseudocolor filters, and negative and direct digital

\footnotetext{
${ }^{1}$ Private Practice

2,3 Department of Dentistry, State University of Maringá, Maringá Brazil

${ }^{4}$ Department of Dentistry, Oral Radiology and Oral Diagnosis Federal University of Sergipe, Sergipe, Brazil

Corresponding Author: Wilton Mitsunari Takeshita, Professor Department of Dentistry, Federal University of Sergipe Department of Dentistry, Claudio Batista s/n-Cidade Universitária Santo Antônio, CEP: 49060-100, Aracaju-Sergipe Brazil, Phone: +55 79 21051821, e-mail: wmtakeshita2@ gmail.com
}

radiography. The pseudocolor filter no. 1 showed statistically significant differences, except at a horizontal angle of $0^{\circ}$, thus indicating lower efficiency in the diagnosis of secondary caries.

Conclusion: Secondary caries with esthetic pulp wall restoration can be diagnosed irrespective of variation in the horizontal angle of incidence of the X-ray beam. The use of different radiographic enhancement filters did not result in improved diagnosis of secondary caries.

Keywords: Bitewing, Dental caries, Digital radiology, Filtered images, Radiography.

How to cite this article: Deprá LC, Iwaki LCV, Chicarelli M, Takeshita WM. Influence of Image Filters and Variation in Horizontal Angle of Incidence of X-ray Beam in Digital Interproximal Radiographs for Diagnosis of Secondary Caries in Esthetic Restorations. J Contemp Dent Pract 2015;16(10): 805-812.

\section{Source of support: Nil}

Conflict of interest: None

\section{INTRODUCTION}

Dental caries disease is a dynamic process that develops as a result of biochemical and ultrastructural changes that culminate in the characteristic clinical signs and symptoms, affects $95 \%$ of the population, and is capable of leading to tooth loss later. So that preventive and not only curative action is taken, the early diagnosis of caries is fundamental. ${ }^{1-3}$ Among dental caries, there are secondary caries, which are the type that occur in intimate contact with restorations and are considered the major cause of loss of restorations. Composite resins are widely used to meet the growing concern about esthetics. Although there have been vast improvements in these materials, there are still some disadvantages to be overcome, such as the occurrence of secondary caries. ${ }^{4}$ 
When restorations are poorly adapted, with irregular margins, fractured or with fractures in the enamel of the cavity preparation margins, they are subject to recurrent caries. As secondary caries frequently present in areas to which access is difficult, or under restorations, they are difficult to diagnose in a clinical exam, and a radiographic exam is essential in order to detect it. ${ }^{4,5}$

The intraoral radiographic technique of choice to help in the diagnosis of secondary caries is the bitewing type. ${ }^{6}$ However, in its initial stages when there is still little loss of mineralized tissue, its detection is difficult, even in interproximal radiographs. With the purpose of improving the diagnostic accuracy of caries, digital radiography was created, with a view to perfecting diagnosis by imaging techniques. ${ }^{7,8}$

There are many factors capable of influencing the early diagnosis of secondary caries, among them the proximity between the carious lesion and restoration, size and direction of the lesion, and the angles of incidence of the main $X$-ray beam $X .{ }^{9,10}$

At present, in seeking to cooperate with caries diagnosis, there are programs that accompany the digital systems and offer image filters that enable an increase in the diagnostic accuracy of the examiner. These programs allow image manipulation, such as adjustment in brightness and contrast, determination of the gray level, inversion of gray tones, application of pseudocolors, among other features. ${ }^{3,11-13}$ Therefore, as far as we know, few studies have compared the different digital image filters in the diagnosis of secondary caries lesions, with the influence of horizontal angulation.

The aim of the present research was to evaluate the accuracy of diagnosing secondary caries artificially created in the pulp wall of premolars with mesio-occlusal-distal (MOD) restorations made with resin composite, by means of digital image filters, with alteration in the horizontal angulation in the interproximal radiographic technique, using a digital radiographic sensor complementary metaloxide-semiconductor (CMOS).

\section{MATERIALS AND METHODS}

\section{Ethics}

The project began after it was approved by the Research Ethics Committee of the State University of MaringaUEM, Protocol No. 71713. This research was conducted in accordance with the Declaration of Helsinki.

\section{Methodology}

The sample was composed of 20 maxillary premolar teeth obtained from the tooth bank, which were donated after surgeries to extract teeth affected by severe periodontal disease, or due to orthodontic indication, performed at the UEM Dental Clinic.

The teeth were disposed in pairs and mounted in 10 blocks (test specimens) made of Aquasil addition silicone (Dentsply ${ }^{\circledR}$, York, PA, USA), with the purpose of keeping them in position and allowing their removal to perform cavity preparation, as the molding material presents flexibility that allows this procedure. The teeth were simultaneously position in a dental arch in the region of premolars, with the proximal surfaces in contact.

After being mounted, each block was radiographed in a 70× Dental X-ray appliance (Dabi Atlante, São Paulo, Brazil), with mechanical calibration previously checked, and with the technical exposurefactors fixed at $70 \mathrm{kVp}, 8 \mathrm{~mA}$, exposure time of $0.2 \mathrm{~s}$, film-focus/receptor distance of $32 \mathrm{~cm}$, selected in a pilot test, in which it was endeavored to define the shortest time capable of producing an ideal image and adequate brightness and contrast principleas low as reasonably achievable (ALARA). For image acquisition, a CMOS sensor, Kodak RVG 6100 (Eastman Kodak, Rochester, NY, USA) brand, positioner of the interproximal radiographic technique developed for adapting the digital sensor, and a $2 \mathrm{~cm}$ thick resin block, interposed between the source of radiation and the tooth, for the purpose of simulating soft-tissue. To standardize positioning, an impression of the bite of the teeth was taken with molding material adhered to the interproximal positioner.

Afterwards, MOD cavity preparations were made in the teeth, and to simulate secondary caries, the cavity pulp wall (occlusal) was submitted to wear with a half spherical carbide bur (carbide bur FG half KG Sorensen), mounted in a high speed handpiece, under constant cooling, and perpendicular to the desired surface. All the defects were made by a single, duly calibrated operator. ${ }^{14,15}$ Based on the research of Ilgüy et al, the orifices were filled with wax and all the teeth were restored with resin composite for posterior teeth Filtek Z350 XT ${ }^{\circledR}$ (3M-ESPE, Dental Products, St. Paul, MN, USA). All the necessary care was taken so that there would be no failures in the restorations, and that good sealing between the tooth/restoration would be obtained. After this, the test specimens were radiographed with a digital sensor, varying the horizontal at intervals of $2^{\circ}$, covering a range from -10 to $+10^{\circ}$.

To generate the images with negative, pseudocolor 1 and pseudocolor 2 image filters, algorithms of the Kodak Dental Imaging 6.1 software program (Carestream Health, Rochester, NY, USA) tools were used (Figs 1A to $\mathrm{D})$. After obtaining the images, they were randomized and evaluated by three examiners with clinical experience 

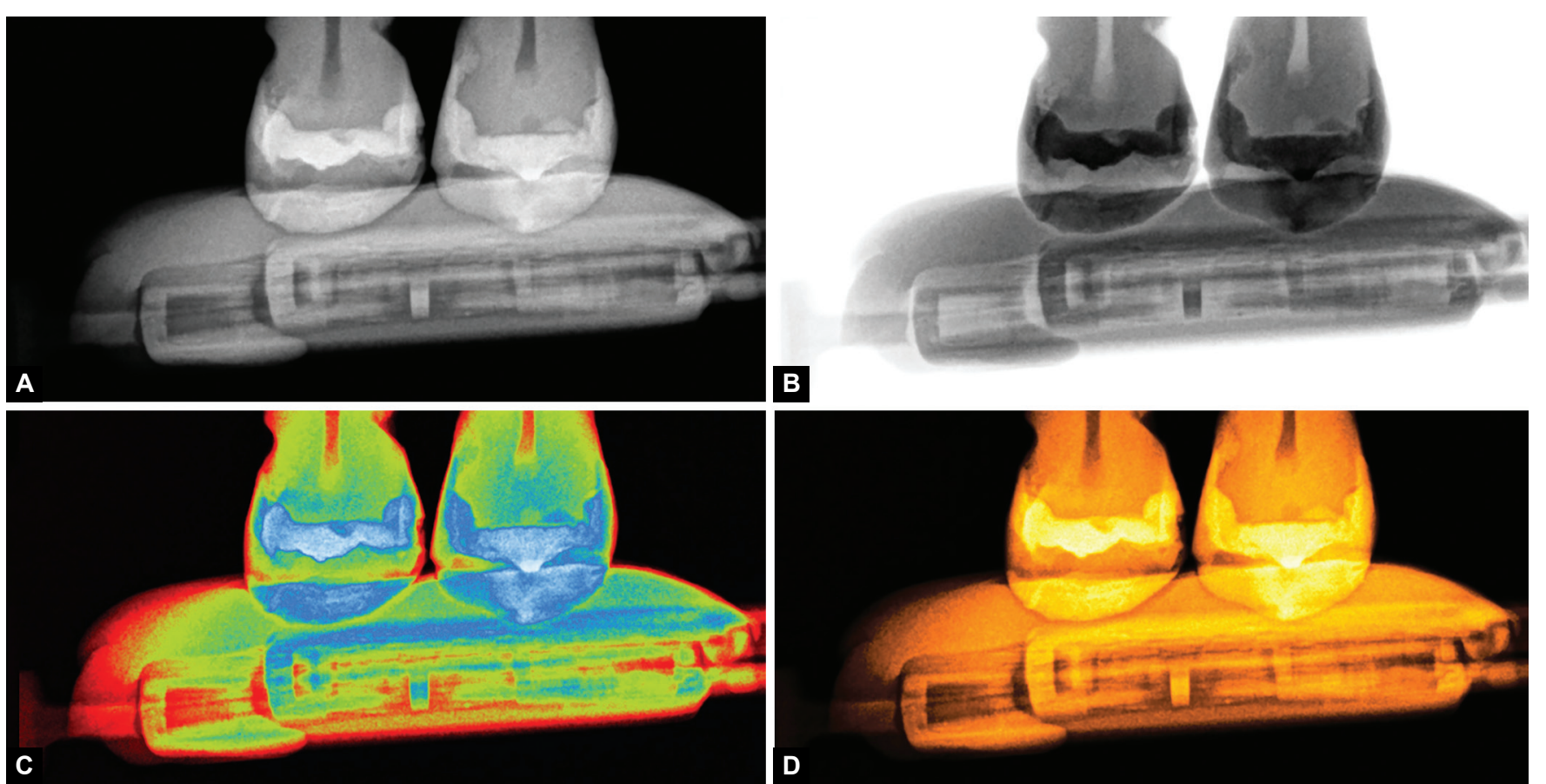

Figs 1A to D: Images of an experimental specimen: (A) direct digital radiography, (B) negative filter, (C) pseudocolor 1 and (D) pseudocolor 2

and specialists in dental radiology, to determine which method was most efficient for the diagnosis of artificially produced secondary caries.

The 440 images were observed in an Intel Core I7 computer (6-GHz RAM, 500-GB hard drive) with an LCD monitor (Model AOC), with standardized brightness and contrast. For evaluation of the images, the Kodak Dental Imaging 6.1 (Carestream Health, Rochester, NY, USA) software program was used, and were classified by the examiners by means of a 5-point scale, as follows: (1) defect definitely present, (2) defect probably present, (3) uncertain, (4) defect probably absent and (5) defect definitely absent. ${ }^{2,3}$

\section{STATISTICAL METHODS}

After evaluation, the data were submitted to statistical analysis (MedCalc 12.3.0 Software, Ostend, Belgium). To verify intra- and interexaminer agreement, the Kappa test was used, and to evaluate the imaging methods, the receiver operator characteristic (ROC) curve at a level of significance of $5 \%$ was used.

\section{RESULTS}

According to the methodology with the ROC curve used to evaluate the imaging methods, the following results were observed, as shown in Tables 1 to 4 , and in Graphs 1 and 2.

According to the Tables and Figures above, at $0^{\circ}$ it could be observed that in spite of pseudocolor 2 presenting lower results than the other radiographic filters, demonstrating a smaller area below the ROC curve, there was no statistically significant difference among them.

When observing the other degrees; that is to say, $2,4,6,8$ and $10^{\circ}$ positive, the radiographic filter that presented the lowest results than all the others, demonstrating the smallest area below the ROC curve, was pseudocolor 1 , with statistically significant difference from pseudocolor 2, negative and DDR at 2, 4 and $6^{\circ}$ positive, only from DDR at $10^{\circ}$ and without statistical difference at the angle of $8^{\circ}$.

With regard to the angles of negative degrees, which may be observed in the Tables and Graphs above (Tables 1 to 4 and Graphs 1 and 2) showing that pseudocolor 1 presented lower efficiency in the diagnosis of secondary

Table 1: Comparison of different imaging methods and different positive angles demonstrating the area below the ROC curve and standard-error

\begin{tabular}{|c|c|c|c|c|c|c|c|c|c|c|c|c|}
\hline \multirow[b]{2}{*}{$\begin{array}{l}\text { Imaging } \\
\text { modality }\end{array}$} & \multicolumn{2}{|c|}{$0^{\circ}$} & \multicolumn{2}{|c|}{$2^{\circ}$} & \multicolumn{2}{|c|}{$4^{\circ}$} & \multicolumn{2}{|c|}{$6^{\circ}$} & \multicolumn{2}{|c|}{$8^{\circ}$} & \multicolumn{2}{|c|}{$10^{\circ}$} \\
\hline & $\begin{array}{l}\text { ROC } \\
\text { curve }\end{array}$ & $\begin{array}{l}\text { St. } \\
\text { error }\end{array}$ & $\begin{array}{l}\text { ROC } \\
\text { curve }\end{array}$ & $\begin{array}{l}\text { St. } \\
\text { error }\end{array}$ & $\begin{array}{l}\text { ROC } \\
\text { curve }\end{array}$ & $\begin{array}{l}\text { St. } \\
\text { error }\end{array}$ & $\begin{array}{l}\text { ROC } \\
\text { curve }\end{array}$ & $\begin{array}{l}\text { St. } \\
\text { error }\end{array}$ & $\begin{array}{l}\text { ROC } \\
\text { curve }\end{array}$ & $\begin{array}{l}\text { St. } \\
\text { error }\end{array}$ & $\begin{array}{l}\text { ROC } \\
\text { curve }\end{array}$ & $\begin{array}{l}\text { St. } \\
\text { error }\end{array}$ \\
\hline $\begin{array}{l}\text { DDR } \\
\text {. }\end{array}$ & 0.879 & 0.047 & 0.887 & 0.045 & 0.895 & 0.031 & 0.902 & 0.030 & 0.869 & 0.035 & 0.909 & 0.029 \\
\hline Negative & 0.897 & 0.043 & 0.898 & 0.043 & 0.894 & 0.031 & 0.889 & 0.032 & 0.903 & 0.030 & 0.910 & 0.029 \\
\hline Color 1 & 0.892 & 0.044 & 0.746 & 0.065 & 0.778 & 0.044 & 0.641 & 0.052 & 0.836 & 0.039 & 0.830 & 0.039 \\
\hline Color 2 & 0.829 & 0.055 & 0.881 & 0.046 & 0.902 & 0.030 & 0.885 & 0.033 & 0.903 & 0.030 & 0.872 & 0.034 \\
\hline
\end{tabular}

DDR: Direct digital radiograph; Negative: Negative image filter; Color 1: Pseudocolor 1 image filter; Color 2: Pseudocolor 2 image filter 
Table 2: Comparison of different imaging methods and different negative angles demonstrating the area below the ROC curve and standard error

\begin{tabular}{|c|c|c|c|c|c|c|c|c|c|c|}
\hline \multirow[b]{2}{*}{ Imaging modality } & \multicolumn{2}{|c|}{$-2^{\circ}$} & \multicolumn{2}{|c|}{$-4^{\circ}$} & \multicolumn{2}{|c|}{$-6^{\circ}$} & \multicolumn{2}{|c|}{$-8^{\circ}$} & \multicolumn{2}{|c|}{$-10^{\circ}$} \\
\hline & $\begin{array}{l}\text { ROC } \\
\text { curve }\end{array}$ & St. error & $\begin{array}{l}\text { ROC } \\
\text { curve }\end{array}$ & St. error & $\begin{array}{l}\text { ROC } \\
\text { curve }\end{array}$ & St. error & $\begin{array}{l}\text { ROC } \\
\text { curve }\end{array}$ & St. error & $\begin{array}{l}\text { ROC } \\
\text { curve }\end{array}$ & St. error \\
\hline DDR & 0.896 & 0.031 & 0.909 & 0.029 & 0.923 & 0.027 & 0.898 & 0.031 & 0.891 & 0.032 \\
\hline Negative & 0.914 & 0.028 & 0.914 & 0.028 & 0.884 & 0.033 & 0.865 & 0.035 & 0.915 & 0.028 \\
\hline Color 1 & 0.822 & 0.040 & 0.771 & 0.045 & 0.633 & 0.052 & 0.782 & 0.044 & 0.823 & 0.040 \\
\hline Color 2 & 0.898 & 0.031 & 0.892 & 0.032 & 0.896 & 0.031 & 0.864 & 0.035 & 0.903 & 0.030 \\
\hline
\end{tabular}

DDR: Direct digital radiograph; Negative: Negative image filter; Color 1: Pseudocolor 1 image filter; Color 2: Pseudocolor 2 image filter

Table 3: Comparisons between areas under the ROC curves of the imaging methods at the different degrees of (positive) angulation

\begin{tabular}{|c|c|c|c|c|c|c|c|c|c|c|c|c|}
\hline \multirow[b]{2}{*}{$\begin{array}{l}\text { Imaging } \\
\text { modality }\end{array}$} & \multicolumn{2}{|l|}{$0^{\circ}$} & \multicolumn{2}{|l|}{$2^{\circ}$} & \multicolumn{2}{|l|}{$4^{\circ}$} & \multicolumn{2}{|l|}{$6^{\circ}$} & \multicolumn{2}{|l|}{$8^{\circ}$} & \multicolumn{2}{|l|}{$10^{\circ}$} \\
\hline & (p-value) & $\begin{array}{l}\text { St. } \\
\text { error }\end{array}$ & (p-value) & $\begin{array}{l}\text { St. } \\
\text { error }\end{array}$ & (p-value) & $\begin{array}{l}\text { St. } \\
\text { error }\end{array}$ & (p-value) & $\begin{array}{l}\text { St. } \\
\text { error }\end{array}$ & (p-value) & $\begin{array}{l}\text { St. } \\
\text { error }\end{array}$ & (p-value) & $\begin{array}{l}\text { St. } \\
\text { error }\end{array}$ \\
\hline $\begin{array}{l}\text { Color } 1 \times \\
\text { Color } 2\end{array}$ & 0.251 & 0.055 & $0.023^{*}$ & 0.060 & $0.003^{*}$ & 0.042 & $0.000^{*}$ & 0.053 & 0.079 & 0.038 & 0.274 & 0.039 \\
\hline $\begin{array}{l}\text { Color } 1 \times \\
\text { Negative }\end{array}$ & 0.918 & 0.049 & $0.018^{*}$ & 0.065 & $0.011^{*}$ & 0.046 & $0.000^{*}$ & 0.055 & 0.084 & 0.039 & 0.061 & 0.043 \\
\hline $\begin{array}{l}\text { Color } 1 \times \\
\text { RDD }\end{array}$ & 0.800 & 0.051 & $0.031^{*}$ & 0.065 & $0.011^{*}$ & 0.046 & $0.000^{*}$ & 0.055 & 0.434 & 0.042 & $0.040^{*}$ & 0.039 \\
\hline $\begin{array}{l}\text { Color } 2 \times \\
\text { Negative }\end{array}$ & 0.156 & 0.048 & 0.681 & 0.042 & 0.784 & 0.029 & 0.895 & 0.031 & 1.000 & 0.032 & 0.230 & 0.032 \\
\hline $\begin{array}{l}\text { Color } 2 \times \\
\text { DDR }\end{array}$ & 0.401 & 0.060 & 0.881 & 0.037 & 0.830 & 0.030 & 0.576 & 0.030 & 0.228 & 0.028 & 0.190 & 0.028 \\
\hline $\begin{array}{l}\text { Negative } \\
\times \text { DDR }\end{array}$ & 0.716 & 0.049 & 0.770 & 0.040 & 0.031 & 0.961 & 0.664 & 0.029 & 0.292 & 0.032 & 0.970 & 0.028 \\
\hline
\end{tabular}

${ }^{*} p<0.05$ statistically significant difference; DDR: Direct digital radiograph; Negative: Negative image filter; Color 1: Pseudocolor 1 image filter; Color 2: Pseudocolor 2 image filter

Table 4: Comparisons between areas under the ROC curves of the imaging methods at the different degrees of (negative) angulation

\begin{tabular}{|c|c|c|c|c|c|c|c|c|c|c|}
\hline \multirow{2}{*}{$\begin{array}{l}\text { Imaging } \\
\text { modality }\end{array}$} & \multicolumn{2}{|c|}{$-2^{\circ}$} & \multicolumn{2}{|c|}{$-4^{\circ}$} & \multicolumn{2}{|c|}{$-6^{\circ}$} & \multicolumn{2}{|c|}{$-8^{\circ}$} & \multicolumn{2}{|c|}{$-10^{\circ}$} \\
\hline & (p-value) & St. error & ( $p$-value) & St. error & (p-value) & St. error & ( $p$-value) & St. error & (p-value) & St. error \\
\hline $\begin{array}{l}\text { Color } 1 \times \\
\text { Color } 2\end{array}$ & $0.037^{*}$ & 0.036 & $0.005^{*}$ & 0.043 & $0.000^{*}$ & 0.054 & 0.051 & 0.042 & $0.037^{*}$ & 0.038 \\
\hline $\begin{array}{l}\text { Color } 1 \times \\
\text { Negative }\end{array}$ & $0.017^{*}$ & 0.038 & $0.002^{*}$ & 0.046 & $0.000^{*}$ & 0.057 & 0.084 & 0.048 & $0.024^{*}$ & 0.040 \\
\hline $\begin{array}{l}\text { Color } 1 \times \\
\text { DDR }\end{array}$ & 0.052 & 0.038 & $0.002^{*}$ & 0.044 & $0.000^{*}$ & 0.054 & $0.011^{*}$ & 0.045 & 0.124 & 0.044 \\
\hline $\begin{array}{l}\text { Color } 2 \times \\
\text { Negative }\end{array}$ & 0.548 & 0.027 & 0.513 & 0.034 & 0.728 & 0.034 & 0.987 & 0.037 & 0.655 & 0.026 \\
\hline $\begin{array}{l}\text { Color } 2 \times \\
\text { DDR }\end{array}$ & 0.956 & 0.028 & 0.515 & 0.026 & 0.327 & 0.028 & 0.317 & 0.034 & 0.692 & 0.031 \\
\hline $\begin{array}{l}\text { Negative } \\
\times \text { DDR }\end{array}$ & 0.538 & 0.028 & 0.882 & 0.033 & 0.195 & 0.030 & 0.326 & 0.034 & 0.435 & 0.031 \\
\hline
\end{tabular}

${ }^{*} p<0.05$ Statistically significant difference; DDR: Direct digital radiograph; Negative: Negative image filter; Color 1: Pseudocolor 1 image filter; Color 2: Pseudocolor 2 image filter

caries at all the negative angulations, showing a smaller area below the ROC curve, and presenting statistically significant difference when compared with pseudocolor 2 and negative at -2 and $-10^{\circ}$, statistically significant difference compared with pseudocolor 2 , negative and RDD at $-4,-6$ and at $-8^{\circ}$, statistically significant difference when compared with DDR using $-8^{\circ}$.
In the analysis in Table 5, which shows the performance in the diagnosis of secondary caries, taking into consideration the angle of incidence of the X-rays, whose values represent the area under the ROC curve in each radiographic filter and the mean value between them, it may be observed that the angulations of $10^{\circ}$ positive and negative obtained the highest mean values. 


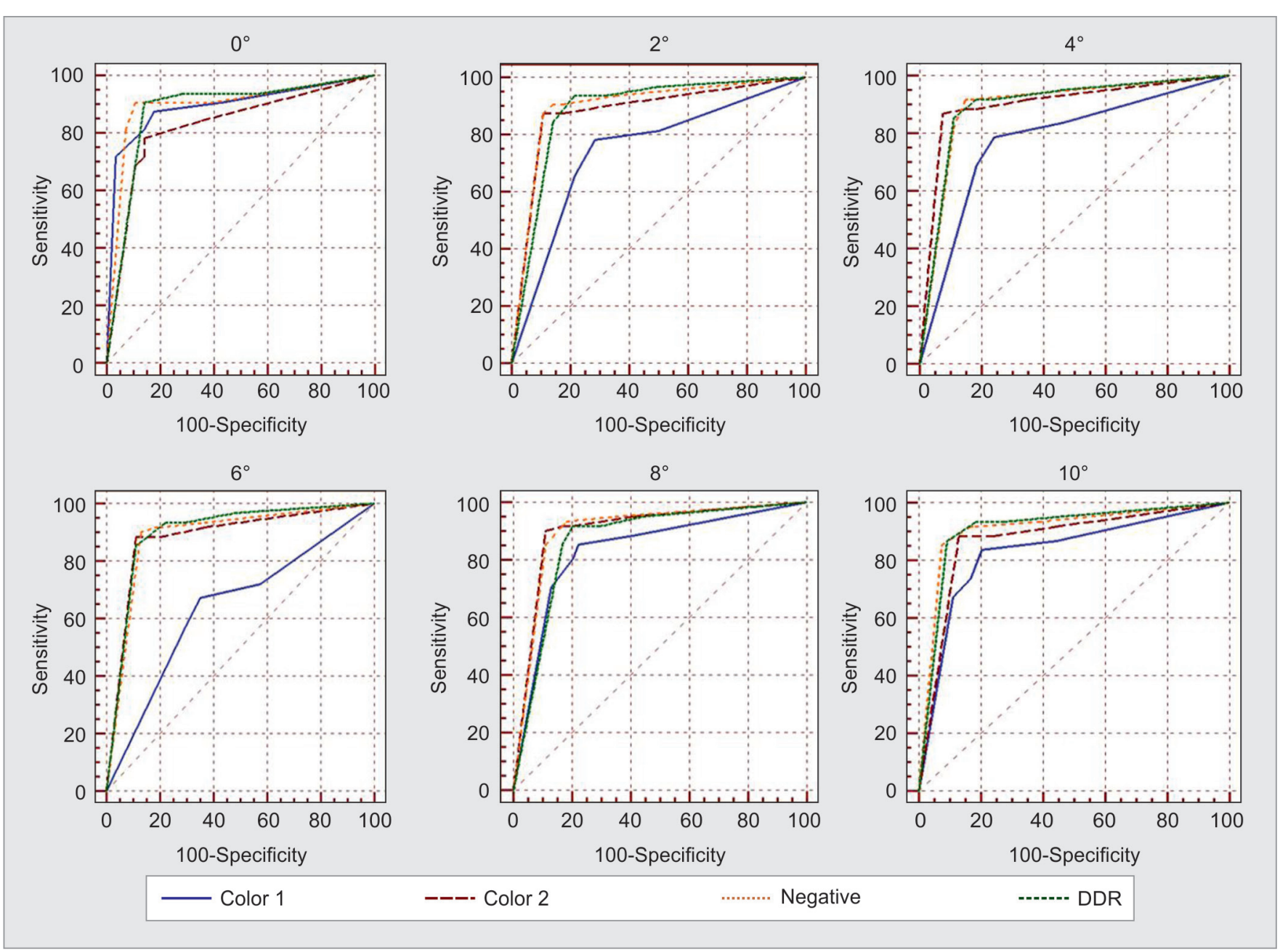

Graph 1: Graphic representation of ROC curve for different methods, at different (zero and positive) angulations (DDR: Direct digital radiograph; Negative: Negative image filter; Color 1: Pseudocolor 1 image filter; Color 2: Pseudocolor 2 image filter)

Table 5: Performance in the diagnosis of secondary caries among the different angles of incidence of the $\mathrm{X}$-ray beams

\begin{tabular}{llllll}
\hline Degree & Color 1 & Color 2 & Negative & DDR & Mean \\
\hline 0 & 0.892 & 0.829 & 0.897 & 0.879 & 0.874 \\
2 & 0.746 & 0.881 & 0.898 & 0.887 & 0.853 \\
4 & 0.778 & 0.902 & 0.894 & 0.895 & 0.829 \\
6 & 0.641 & 0.885 & 0.889 & 0.902 & 0.829 \\
8 & 0.836 & 0.903 & 0.903 & 0.869 & 0.878 \\
10 & 0.830 & 0.872 & 0.910 & 0.909 & 0.880 \\
-2 & 0.822 & 0.898 & 0.914 & 0.896 & 0.872 \\
-4 & 0.771 & 0.892 & 0.914 & 0.909 & 0.872 \\
-6 & 0.633 & 0.896 & 0.884 & 0.923 & 0.834 \\
-8 & 0.782 & 0.864 & 0.865 & 0.898 & 0.852 \\
-10 & 0.823 & 0.903 & 0.915 & 0.891 & 0.883 \\
\hline
\end{tabular}

DDR: Direct digital radiograph; Negative: Negative image filter; Color 1: Pseudocolor 1 image filter; Color 2: Pseudocolor 2 image filter

\section{DISCUSSION}

The method most frequently used for the diagnosis of caries that is inaccessible to clinical exam continues to be the radiographic exam. Moreover, at present conventional films are being replaced by digital radiography. ${ }^{16,17}$ Among the advantages of digital radiography is the possibility of manipulating the images captured, by means of software programs and radiographic filters, with the purpose of improving the image quality, and enabling better analysis of its content., 3,17 The present article evaluated the different filters associated with different horizontal angulations in interproximal radiographs with simulated secondary caries in teeth restored with resin composite.

In this study analysis with ROC curve were used to evaluate the effect of negative, pseudocolor 1 and pseudocolor 2 filters on the diagnosis of occlusal secondary caries. An advantage of the ROC analysis is that it reflects the diagnostic performance of the method based on sensitivity and specificity. 5,11,19

These groups were evaluated by three examiners, specialists in Dental Radiology and Imaging Exams, suing the scale of evaluation, whose data were submitted to the Kappa interexaminer $(K W=0.799)$ and intraexaminer tests: examiner $\mathrm{A}(\mathrm{KW}=0.817)$, examiner $\mathrm{B}(\mathrm{KW}=0.931)$ and examiner $C(K W=0.841)$. In order to interpret these results Landis and Koch, ${ }^{20}$ presented a scale that goes from $<0$ up to 1.00 , with the interval between 1.00 and 0.81 representing almost perfect agreement and between 


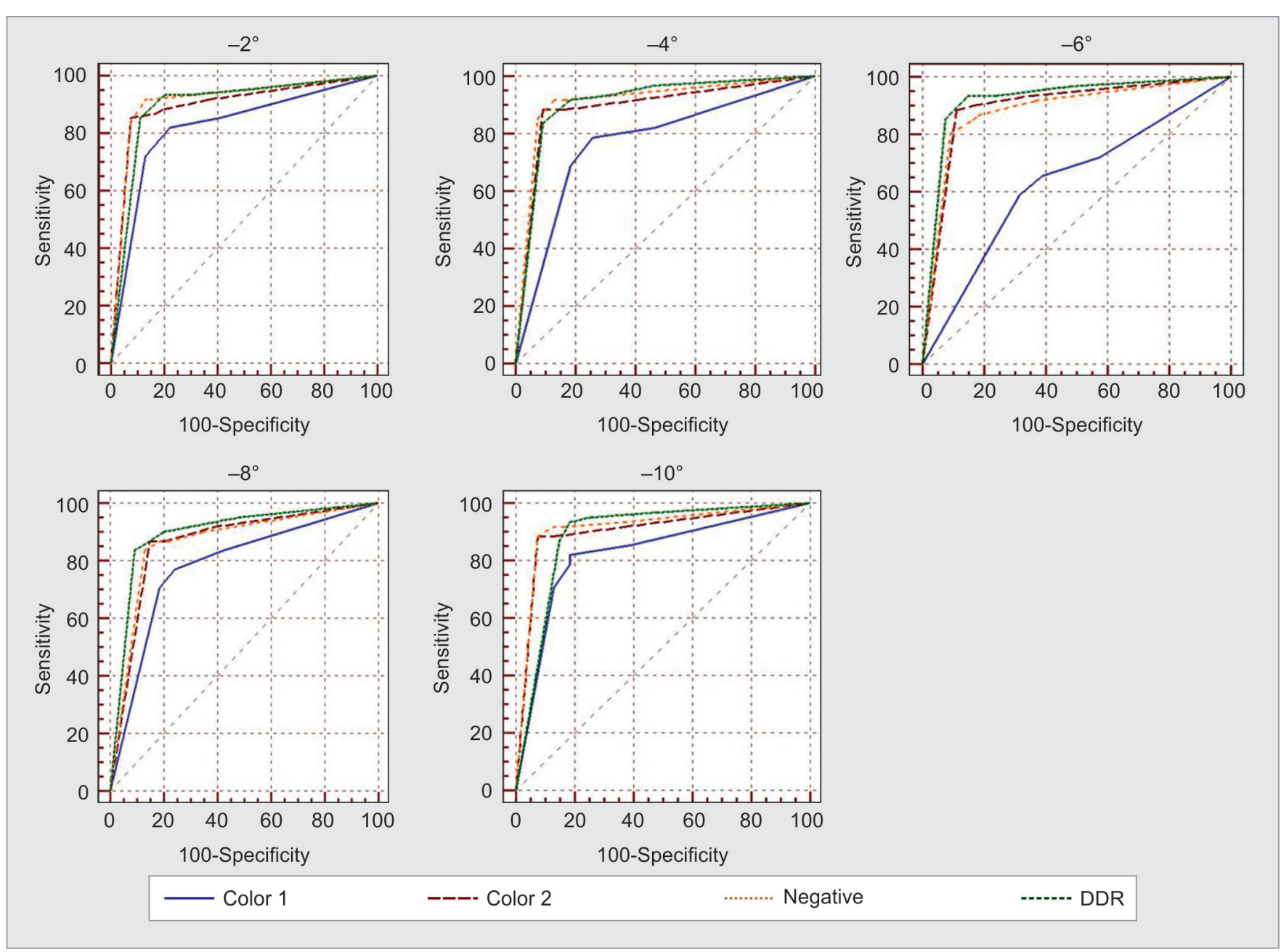

Graph 2: Graphic representation of ROC curve for different methods, at different (negative) angulations

0.80 and 0.61 substantial agreement. Therefore, the fact that three specialist examiners were used in the study, certainly had a positive influence on the results obtained, bearing in mind that almost perfect agreement between the examiners was found.

As seen in the results presented in the present manuscript, the application of different radiographic filters did not result in an improvement in the diagnosis of caries, corroborating the results found by Takeshita $\mathrm{et}^{3}{ }^{3}$ Haiter-Neto et $\mathrm{al}^{13}$ Booshehry et $\mathrm{al}^{17}$ Belém et $\mathrm{al}^{19}$ and Haak et al. ${ }^{21}$ Nevertheless, results differing from those in the present manuscript were obtained by Sanden et $\mathrm{al}^{7}$ Akarslan et al, ${ }^{9}$ who concluded that image manipulation with the use of filters improved the diagnostic accuracy and resulted in statistically significant differences when compared with digital images without filters.

While the direct digital radiographs and pseudocolor 2 and negative filters presented no significant differences, the radiographs presented in pseudocolor 1 showed significant differences at all the angles of incidence of the X-ray beam, with the exception of zero and $8^{\circ}$ positive, with the latter, therefore, being the worst filter to be used during the investigation of secondary caries.
The pseudocolor mode applies different colors to some of the gray scales, and may potentiate some points of contrast. Studies evaluating the changes in alveolar bone density have pointed out greater inter- and intraobserver agreement in comparison with black and white subtraction images. ${ }^{22,23}$ In this study, the effect of different radiographic filters on image interpretation was evaluated. Other studies have use different digital image resources or influence of exposure factors, but few have studied the effect of image manipulation on the diagnosis of occlusal caries. This variety of studies with different methods and materials generates different results, and limits comparison with this study.

The software programs analyzed alter the images to improve their interpretation, but studies have pointed out that these do not present satisfactory results, considering the time necessary for image manipulation and uncertainty as regards their faithfulness. A possible explanation for why there is no significant advantage with the use of different radiographic filters available in software programs, or even a disadvantage, such as pointed out in the results of the evaluation of images presented in pseudocolor 1 , is the fact that dentists are accustomed 
to interpreting direct digital radiographs and are not familiar with radiographic images in color or negative (with filters), thus not increasing the efficiency of their analysis and interpretation. ${ }^{24-26}$

After comparison between the results, according to the angle of incidence of the X-ray beams, taking into account the area below the ROC curve and the mean value obtained with the different radiographic filters, it was found that the variation in the angle of incidence of the X-ray beams did not influence the diagnosis of secondary caries on the pulp cavity wall of premolars. As the secondary caries were artificially created on the cavity pulp walls, the variation of $10^{\circ}$ in the incidence of the X-ray beam did not generate superimposition of images, thus not influencing the diagnosis of these lesions. Van der Stelt ${ }^{15}$ evaluated the influence of the variation in the angle of incidence of the $X$-ray beams on the detection of artificially created proximal caries, and found that radiographs in which the incidence of the X-ray beam was perpendicular to the tooth surface obtained better results in the diagnosis of proximal caries, than those in which there was a change in the horizontal angle of incidence. Therefore, the diagnosis of secondary caries would be more influenced by the angle of incidence of $X$-ray beams in cases of carious lesions in proximal regions, in which superimposition of dental structures would occur.

In spite of various image resources available in software programs being capable of changing the radiographic images with the purpose of improving the diagnosis of caries and other lesions in the dental and adjacent structures, there was no clear advantage in the diagnosis of secondary caries on the pulp cavity wall of premolars with the use of negative, pseudocolor 1 and pseudocolor 2 radiographic filters, in comparison with normal radiographs in gray scales. It is believed that radiographic filters will present better results in the diagnosis of caries, as professionals become more familiarized with these resources. Variation in the horizontal angle of incidence of X-ray beams did not influence the diagnosis of secondary caries on the pulp cavity wall of premolars. A study with lesion in the proximal region would probably have more conclusive results as regards the influence of horizontal angulation on the diagnosis of secondary caries, therefore the present manuscript provides a basis for the development of future research studies to evaluate variables that were not evaluated in the present study.

\section{CONCLUSION}

Bearing in mind the purpose and the results obtained, it could be concluded that:
- Secondary caries on the pulp chamber wall could be diagnosed independently of the variation in the horizontal angle of incidence of the X-ray beam.

- The use of different radiographic filters did not result in an improvement in the diagnosis of secondary caries.

\section{ACKNOWLEDGMENT}

The authors thank the 'Fundação Araucária' for financing the present research study PIBIC/FUNDAÇÃO ARAUCÁRIA-UEM.

\section{REFERENCES}

1. Wenzel A. Digital imaging for dental caries. Dental Clinics of North America 2000;44:319-338.

2. Wenzel A, Hintze H, Kold LM, Kold S. Accuracy of computerautomated caries detection in digital radiographs compared with human observers. Europ J Oral Sci 2002;110:199-203.

3. Takeshita WM, Iwaki LCV, Silva MC, Iwaki-Filho L, Queiroz AF, Geron LBG. Comparison of the diagnostic accuracy of direct digital radiography system, filtered images and subtraction radiography. Contempor Clin Dentist 2013;4:338-342.

4. Kirkevang LL, Vaeth M, Wenzel A. Prevalence and incidence of caries lesions in relation to placement and replacement of fillings: a longitudinal observational radiographic study of an adult Danish population. Caries Res 2009;43:286-293.

5. Kositbowornchai S, Sukanya C, Tidarat T, Chanoggarn T. Caries detection under composite restorations by laser fluorescence and digital radiography. Clin Oral Invest 2013;17:2079-2084

6. Janhom A, van Ginkel FC, van Amerongen JP, van der Stelt PF. Scanning resolution and the detection of approximal caries. Dentomaxillofac Radiol 2001;30:166-171.

7. Sanden E, Koob A, Hassfeld S, Staehle HJ, Eickholz P. Reliability of digital radiography of interproximal dental caries. Am J Dentist 2003;16:170-176.

8. Van der Stelt P. Better imaging: the advantages of digital radiography. J Am Dentist Assoc 2008;139:7S-13S.

9. Akarslan ZZ, Akdevelioğlu M, Güngör K, Erten H. A comparison of the diagnostic accuracy of bitewing, periapical, unfiltered and filtered digital panoramic images for approximal caries detection in posterior teeth. Dentomaxillofac Radiol 2008;37:458-463.

10. Anbiaee N, Mohassel AR, Imanimoghaddam M, MoazzamiSM. A comparison of the accuracy of digital and conventional radiography in the diagnosis of recurrent caries. J Contempor Dent Pract 2010;11:25-32.

11. Kositbowornchai S, Basiw M, Promwang Y, Moragorn H, Sooksuntisakoonchai N. Accuracy of diagnosing occlusal caries using enhanced digital images. Dentomaxillofac Radiol 2004;33:236-240.

12. Alves WEGW, Ono E, Tanaka JLO, Medici-filho E, Moraes LC, Moraes MEL, Castilho JCM. Influence of image filters on the reproducibility of measurements of alveolar bone loss. J Appl Oral Sci 2006;14:415-420.

13. Haiter-Neto F, dos Anjos Pontual A, Frydenberg M, Wenzel A. Detection of noncavitated approximal caries lesions in digital 
images from seven solid-state receptors with particular focus on task-specific enhancement filters. An ex vivo study in human teeth. Clin Oral Investigations 2008;12:217-223.

14. İlgüy M, Dinçer S, İlgüy D, Bayirli G. Detection of artificial occlusal caries in a phosphor imaging plate system with two types of LCD monitors versus three different films. J Digi Imag 2009;22:242-249.

15. Van der Stelt PF, Tuttiman UE, Webber RL, Heemstra P. In vitro study into the influence of $X$-ray beam angulation on the detection of artificial caries defects on bitewing radiographs. Car Res 1989;23:334-341.

16. Seneadza V,Koob A, KaltschmittJ, StaehleHJ, Duwenhoegger J, Eickholz P. Digital enhancement of radiographs for assessment of interproximal dental caries. Dentomaxillofac Radiol 2008;37:142-148.

17. Booshehry MZ, Davari A, Ardakani FE, Nejad MRR. Efficacy of application of pseudocolor filters in the detection of interproximal caries. J Dent Res Dent Clin Dent Prosp 2010;4:79-82.

18. White SC, Pharoah MJ. Oral radiology: principles and interpretation. 6th ed. St. Louis: Mosby/Elsevier 2009;109-151.

19. Belém MD, Ambrosano GM, Tabchoury CP, FerreiraSantos RI, Haiter-Neto F. Performance of digital radiography with enhancement filters for the diagnosis of proximal caries. Braz Oral Res 2013;27:245-251.

20. Landis JR, Koch GG. The measurement of observer agreement for categorical data. Biometrics 1977;33:159-174.

21. Haak R, Wicht MJ, Noack MJ. Conventional, digital and contrast enhanced bite wing radiographs in the decision to restore approximal carious lesions. Caries Res 2001;35:193-199.

22. Bragger U, Pasquali L. Color conversion of alveolar bone density changes in digital subtraction images. J Clin Periodontol 1989;16:209-214.

23. Shi XQ, Eklund I, Tronje G, Welander U, Stamatakis HC, Engstrom PE, et al. Comparison of observer reliability in assessing alveolar bone changes from color-coded with subtraction radiographs. Dentomaxillofac Radiol 1999;28:31-36.

24. Nair MK, Nair UP. An in vitro evaluation of Kodak Insight and Ektaspeed Plus film with a CMOS detector for natural proximal caries: ROC analysis. Car Res 2001;35:354-359.

25. Khan EA, Tyndall DA, Ludlow JB, Caplan D. Proximal caries detection: sirona sidexis versus Kodak Ektaspeed Plus. Gen Dentist 2005;53:43-48.

26. Erten H, Akarslan ZZ, Topuz O. The efficiency of three different films and rodiovisography in detecting approximal carious lesions. Quintessence Int 2005;36:65-70. 